\title{
Indicators of Success for Mine Site Restoration in Tropical Moist Forest Ecosystems
}

\author{
D.A. Jasper Outback Ecology Services, Australia
}

E.J. Veneklaas The University of Western Australia, Australia

O.G. Nichols Environment Management and Research Consultants, Australia

D.J. Tongway School of Resources, Environment and Society, Australian National University, Australia

\section{INTRODUCTION}

Ecosystems in the tropics can vary substantially, despite occurring in the same latitudinal zone. However, a common feature is their high biodiversity, with more than $50 \%$ of all plant and animal species being found in tropical forests, despite only occupying $7 \%$ of the land area (Whitmore, 1984). Tropical moist forests are generally defined by rainfall exceeding $1700 \mathrm{~mm}$ annually, an even distribution of solar radiation and constant high temperatures (Grainger, 1993, in Holl and Cairns, 2002). Rainfall is evenly distributed throughout the year in some tropical moist forests, such as at the Ok Tedi mine site in Papua New Guinea, while others may have a distinct dry season (Holl and Cairns, 2002).

Information regarding restoration of tropical forest ecosystems is relatively sparse, especially relating to restoration after mining. It is noteworthy that a review by Hartshorn and Whitmore (1999) only included one paper relating to mining rehabilitation (Parrotta and Knowles, 1997). Most tropical forest restoration literature focuses on abandoned farmland (Holl and Cairns, 2002), and on the development of forestry and agroforestry systems, aiming at maximizing productivity of a limited number of economically-important species (Parrotta, 2002). It has been less common for restoration projects to aim at creating a diverse ecosystem of locally-occurring species that resembles that believed to formerly occupy the landscape.

In this paper, we review indicators that may have application in assessing mine rehabilitation in tropical moist forests, in the context of experience at mines on Misima Island and at Ok Tedi.

\section{RESTORATION PRACTICE FOR TROPICAL FOREST ECOSYSTEMS ON MINED LANDS}

Information for this review of strategies for restoration of tropical moist forests on mined lands was collected from a total of 16 mine sites. The mines were located predominantly in South-East Asia (9) or the Pacific (4), with the remainder from South America and Madagascar. The mining operations included relatively shallow strip mining (bauxite, coal, lateritic nickel, mineral sands, tin) and open-pit mining (gold, copper). The lowest rainfall of the sites reported was $1695 \mathrm{~mm}$ (Poços de Caldas, Brazil), with a maximum of 8000 $\mathrm{mm}$ (Grasberg, West Papua) and a median value around $2800 \mathrm{~mm}$. Details on sites and restoration strategies are given in Jasper et al. (2003). The pre-mining ecosystems varied substantially, reflecting the substantial range in rainfall and soil type, but most forests were evergreen.

The nature of the rehabilitation objectives at each of the operations studied is substantially influenced by the anticipated needs of the local communities or government agencies. For example, rehabilitation outcomes may include garden land or agriculture for local use (e.g. Misima, Grasberg) or plantation forestry (e.g. PT Arutmin, Kalimantan). In Madagascar, demand from the local population for resources such as wood for fuel has required intensive community consultation, to ensure that revegetation success is not compromised (Vincelette, 2003).

In areas where local demand for use of the land is not a primary driver of final land use, the rehabilitation objective is often to establish a forest with similar ecosystem function to that occurring, or believed to have occurred, prior to mining. A current example is that of Kelian Equatorial Gold in Kalimantan, which aimed 
to establish a rainforest that could sustain low impact uses, using simultaneous plantings of dominant species from the structural layers of the adjacent rainforest (McGuire and Green, 2000) PT Kaltim Prima Coal (KPC) in Kalimantan had a similar objective, which was to restore a lowland Dipterocarp rainforest ecosystem, with management requirements no greater than the surrounding forest, and which provides water catchment protection, biodiversity conservation, and forest products (EMRC, 1999a). At sites such as PT Arutmin and PT Inco, both in Indonesia, a transition in rehabilitation objectives over time is evident, with increasing emphasis on re-establishing endemic species, which may have been lost from adjacent areas.

\section{MONITORING APPROACHES AND PERFORMANCE INDICATORS FOR RESTORED TROPICAL ECOSYSTEMS}

\subsection{Introduction}

Long timeframes are required for a rehabilitated ecosystem to achieve levels of species diversity, resilience and ecosystem function that may be considered satisfactory in relation to natural analogues. However, it is not practical to wait for that length of time to determine if rehabilitation was successful. Tongway et al. (1997) and Tongway and Murphy (1999) proposed that rehabilitation passes through a series of identifiable phases and that a series of short-term objectives can be monitored over time, leading to achieving the overall mine site rehabilitation objective (Figure 1). This framework identifies the rational sequence of tasks and objectives that need to be attended to. Although this framework was not directed specifically at tropical moist forests, the principles apply equally.

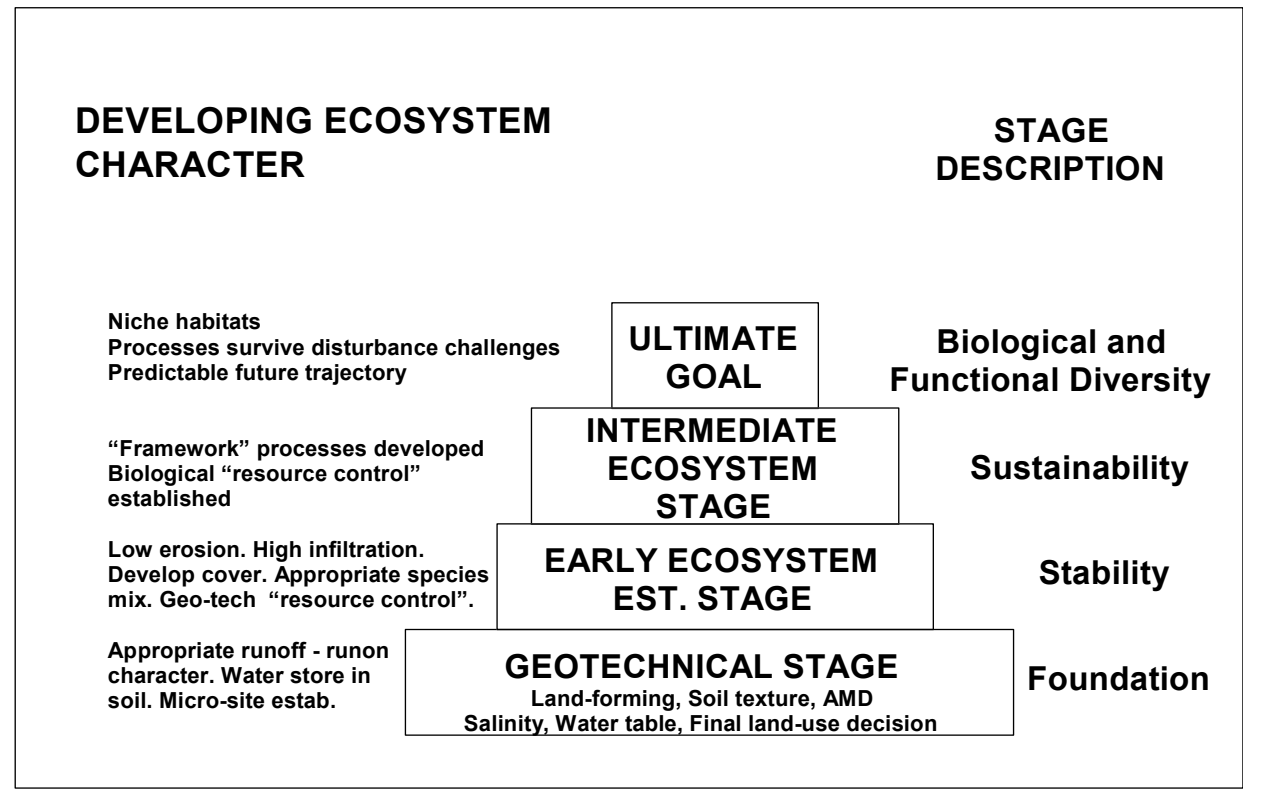

Figure 1 A conceptual framework showing short and long term objectives (after Tongway and Murphy, 1999), implying a shift of emphasis over time in monitoring and a need to make use of a suite of indicators

The framework indicates that issues such as acid-forming mine waste, salinity, dispersive soils, topsoil management and landform design need to be addressed first, before going on to species selection and seeding/planting procedures. Soil/spoil testing for appropriate properties such as proposed in Table 1 needs to be done at this stage. If any properties need modification or isolation, this is the time to do this. Figure 1 directs early monitoring to be focused on landform and soil stability; that this be progressively superseded by monitoring the species composition and growth of colonizing biota. At later stages of ecosystem development, the supply of ecosystem "goods and services" by establishing biota needs to be taken into account as the system becomes more complex and interacting. Finally, the framework proposes that survival 
of stress and disturbance impacts is a critical ecosystem development stage. Such a framework needs to be serviced by a well thought-out set of indicators, able to record progress but also able to provide evidence of "stalling" or potential failure.

Information on the specific monitoring approaches for tropical moist forest restoration after mining is sparse. However, in cases where there is a defined product, such as timber, there are often well-defined assessment methods. From the more general perspective of forest ecology, there are only a few tropical forests around the globe that have been intensively researched, and long-term data sets tend to be limited to tree populations (Losos \& Leigh, 2004). In most cases there is a lack of information on other plants, animals and microorganisms, and particularly on processes like nutrient cycling, soil development, and community dynamics in regenerating forests after other land uses.

\subsection{Assessing Initial Conditions for Rehabilitation}

An essential precursor to measuring rehabilitation performance is to ensure that the foundations of the rehabilitation are correct (Figure 1). Aspects of interest should include those intrinsic chemical and physical soil properties that are unlikely to change over time, and therefore will represent an on-going influence on ecosystem development. For example, in a natural tropical forest environment, the make-up of plant communities may strongly reflect soil depth, soil type, landform and landscape position. While vegetation communities are the visible outcome of mine rehabilitation, and thus are a logical focus of rehabilitation planning, successfully establishing specific communities can only be achieved if an appropriate soil environment has been created. The soil conditions created and the species established at the outset can have lasting impact on ecosystem development and functioning (Chambers et al., 1994).

The capacity of a soil to accommodate water entry, resist structural degradation and support plant growth are key functions (Karlen et al., 1994) that are determined by the soil's physical, chemical and biological properties. Therefore, appropriate soil properties need to be well understood prior to rehabilitation to ensure that they are suitable for the target plant community to be re-established. Alternatively, establishment of a better-adapted plant community may need to be considered. Once vegetation is established, soil properties tend to improve through the impact of plants on soil structure, nutrient availability and soil organisms.

The information that is publicly available for tropical forest restoration on mined land suggests that monitoring is centred around classical botanical measures including plant density, species richness and diversity, and foliar and litter cover. At each site, specific monitoring programmes are likely to be directed towards their local rehabilitation objectives. Typically, these are defined in terms of the end-product, so that intermediate stages are not clearly recognized or defined. However, as with most mine rehabilitation scenarios, achieving a fully-functional ecosystem takes time, and measures are required that reflect trends and have a predictive capability. For this reason, at Misima and Kelian, approaches such as Landscape Function Analysis (LFA) (Tongway and Hindley, 1995, 2004) have been investigated (see Section 3.7).

\subsection{Performance Indicators}

A key principle in selecting indicators of rehabilitation performance, as recommended by Ehrenfeld (2000), is to identify the dominant influencing factor(s) in the rehabilitated ecosystem, and to then focus on restoring appropriate components of the ecosystem which are required to manage the impact of that factor. These dominant, or limiting, factors could be wind or water (physical) or aspects of soil chemistry or physics. For example, in rehabilitation of nutrient-poor soils after bauxite mining in south-west Australia, substantial research has taken place to ensure that adequate pools of limiting nutrients are re-established and to understand the patterns of recovery of those pools over time (Ward and Koch, 1996; Ward, 2000).

Indicators that measure key components of early development in ecosystems are particularly important. The challenge is to identify indicators that are both meaningful and practical to measure. Some important requirements of indicators as identified by Jasper et al. (2003) are as follows.

- Ease of capture.

- Manageable sampling intensity.

- Low error associated with measurement, including reliable data capture from different observers. 
- Interpretation criteria available: no ambiguity in interpretation.

- Local reference data available.

- Responsive in appropriate timeframes.

- Significant for rehabilitation outcomes.

Suitable indicators are those that demonstrate, over time, whether ecological processes are trending in a direction that is appropriate for successful rehabilitation. It is clearly implied that knowledge of the levels of that indicator in appropriate reference sites, and their pattern of recovery during ecosystem development, need to be known. A selected suite of indicators is required simply because it is not possible to measure all aspects of an ecosystem, and the ecosystem parameters that need assessment also change over the longer term. By measuring the selected indicators, the relative scale of broader, more-complex processes should be able to be inferred. It is also important that the indicators are not simply used to identify a problem, but can be used to facilitate correction of the problem, and enable continuous improvement.

The number of possible quantitative measures of ecosystem properties and development of ecosystem processes is substantial and diverse. For example, Jasper et al. (2003) reviewed more than 40 research papers dealing with soil quality in agriculture or mine rehabilitation and identified 58 individual measures of soil properties or processes, including 22 physical measures, 15 chemical and 21 biological. Those considered most useful are presented in Table 1.

Table 1 Summary of monitoring parameters considered most suitable for use in rehabilitation of tropical forest ecosystems, by Jasper et al. (2003)

\begin{tabular}{|c|c|c|c|}
\hline \multicolumn{2}{|c|}{$\begin{array}{l}\text { Soil Parameter } \\
\text { (P- planning phase; M- monitoring phase) }\end{array}$} & $\begin{array}{l}\text { Vegetation parameter } \\
\text { (all monitoring phase) }\end{array}$ & $\begin{array}{l}\text { Fauna parameters } \\
\text { (all monitoring phase) }\end{array}$ \\
\hline Texture & $P$ & Stand height (growth) & Bird species richness \\
\hline Water-holding capacity & $\mathrm{P}$ & Stand basal area (growth) & Total bird abundance \\
\hline Slaking & $\mathrm{P}$ & Tree density & Bird species diversity \\
\hline Dispersion & $P$ & Tree species richness & Presence/absence of \\
\hline C.E.C. & $\mathrm{P}$ & Tree diversity index & early, mid, or late \\
\hline Bulk density & PM & Rank abundance diagram & species \\
\hline Penetration resistance & PM & Understorey cover & Density of key \\
\hline E.C. & PM & Canopy cover & mammal spp. \\
\hline $\mathrm{pH}$ & PM & Leaf litter production & Ants species richness \\
\hline Total and available N,P, K, S & $\mathrm{PM}$ & Relative abundance of & Total ant abundance \\
\hline Structure & M & $\begin{array}{l}\text { planted and unplanted } \\
\text { species }\end{array}$ & \\
\hline Aggregate stability & M & Relative abundance of & \\
\hline Depth of rooting or "soil" & M & desirable and & \\
\hline Total litter & M & undesirable species & \\
\hline Total organic C & M & $\begin{array}{l}\% \text { tree species with } \\
\text { seedlings }\end{array}$ & \\
\hline Litter nutrient content & M & $\begin{array}{l}\text { \# newly-colonising tree } \\
\text { species }\end{array}$ & \\
\hline
\end{tabular}




\subsection{Soil Indicators}

Providing that the materials or soils used to reconstruct a landform after mining are not chemically hostile to plant growth, then issues of landform stability, surface erosion, available nutrients, and the capacity for the soil to accept water and make it available for plant uptake, will be the key soil factors influencing rehabilitation performance, as outlined in the introduction to this section (see above) (Table 1).

Indicators for soils in rehabilitation need to be considered in the context of two stages of the rehabilitation process; planning and monitoring. Firstly, some indicators are required in the planning phase to confirm that the soil or waste is appropriate material for rehabilitation and that it is suitable for seed germination and plant growth (Table 1). The second stage is the use of soil indicators for monitoring during rehabilitation, measuring progress in developing a functional rainforest ecosystem, for example, soil organic matter and nutrient cycling (Table 1).

As discussed in earlier sections, a key driver for (re-)establishing desirable soil properties such as structure and soil particle aggregation, and biological processes such as mineralization, is plant productivity. Plant productivity in turn reflects the underlying chemical, physical and biological fertility of the soil, including the functioning of the nutrient cycle. Suitable intrinsic soil properties are essential, but may need to be complemented with additional inputs perhaps from fertilizer, organic amendments, or legume-mediated nitrogen inputs, to ensure appropriate nutrient availability and to restore nutrient pools for a self-sustaining forest ecosystem. Only $\mathrm{N}$ pools may be expected to increase during rehabilitation, due to inputs from legumes (e.g. Ward and Koch, 1996).

Within many tropical rain forest ecosystems, particularly highly-leached, nutrient-poor soils, the major proportion of the nutrient capital is incorporated in plant biomass and the forest floor (Grubb, 1989; Burghouts et al., 1992), and the ecosystem is considered to effectively function with a closed and tightly controlled nutrient cycle (Burnham, 1989). Decomposition of litter, the release of nutrients and their effective uptake by plant roots is therefore an important pathway in the rain forest nutrient cycle. The tropical environment favours a high level of biological activity, including the continuous production of organic matter by the vegetation and rapid degradation by macro- and micro-organisms in the surface soil (Burnham, 1984; Lavelle, 1997). Clearly, the level of production of plant biomass and hence the input of plant litter to the forest floor, as well as its processing, are important overall indicators of rehabilitation success and these measures will reflect the suitability of the original soil growing medium for plant growth. The development of root systems, inputs of organic matter from roots and litter, and the activities of soil animals all contribute to the development of soil structure, and could be expected to be reflected in improved soil structure, aggregate stability and decreasing soil strength and bulk density (Table 1). These properties can be measured directly, for example soil penetrability was measured as a research tool at the Poços de Caldas bauxite mine (Majer, 1996). At Kelian and Misima, fast-growing ground-hugging vines rapidly provided complete ground cover with immediate positive flow-on to low erosion and higher infiltration due to the soil not being crusted. Landscape Function Analysis (see Section 3.7) also represents an indirect estimate of change in these properties, given that it integrates many of the "plant-driven" properties to create indices of soil stability and infiltration.

\subsection{Vegetation Indicators}

There is very limited knowledge of the revegetation ecology of tropical forests after such drastic disturbances as mining, particularly in south-east Asia and Papua New Guinea. Strategies and assessment must therefore be based on general ecological principles. In the context of vegetation, Jasper et al. (2003) considered critical features of successfully rehabilitated tropical forests to include species richness and diversity, with species composition reflecting variation in site conditions, functionality including resource retention, biomass production, and reproduction and recruitment; and development from a multi-species plantation into a self-sustaining complex ecosystem.

As flagged above, a key measure of adequacy of the soil medium for rehabilitation is the productivity of the vegetation. Natural recovery of tropical moist forests on former farmland typically can reach equivalent plant biomass and species richness within a period of 15 to 60 years (Holl and Cairns, 2002). In a review of more than 130 studies of carbon accumulation in secondary forests growing on what had been cleared land, Silver et al. (2000) demonstrated that typically these forests reach $25 \%$ of their final above-ground biomass 
within 10 years, and 50\% in 20 years (Figure 2). In the first 20 years, the secondary forests accumulated biomass at an average rate of $6.2 \mathrm{t} / \mathrm{ha} / \mathrm{yr}$, with a long-term rate of $2.36 \mathrm{t} / \mathrm{ha} / \mathrm{yr}$ (Silver et al., 2000). The actual biomass reached was greatest on former agricultural land and least on land that had been cleared and abandoned (Silver et al., 2000). It must be noted, however, that the dataset for cleared and abandoned land was very small and largely limited to sites aged 1-3 years.

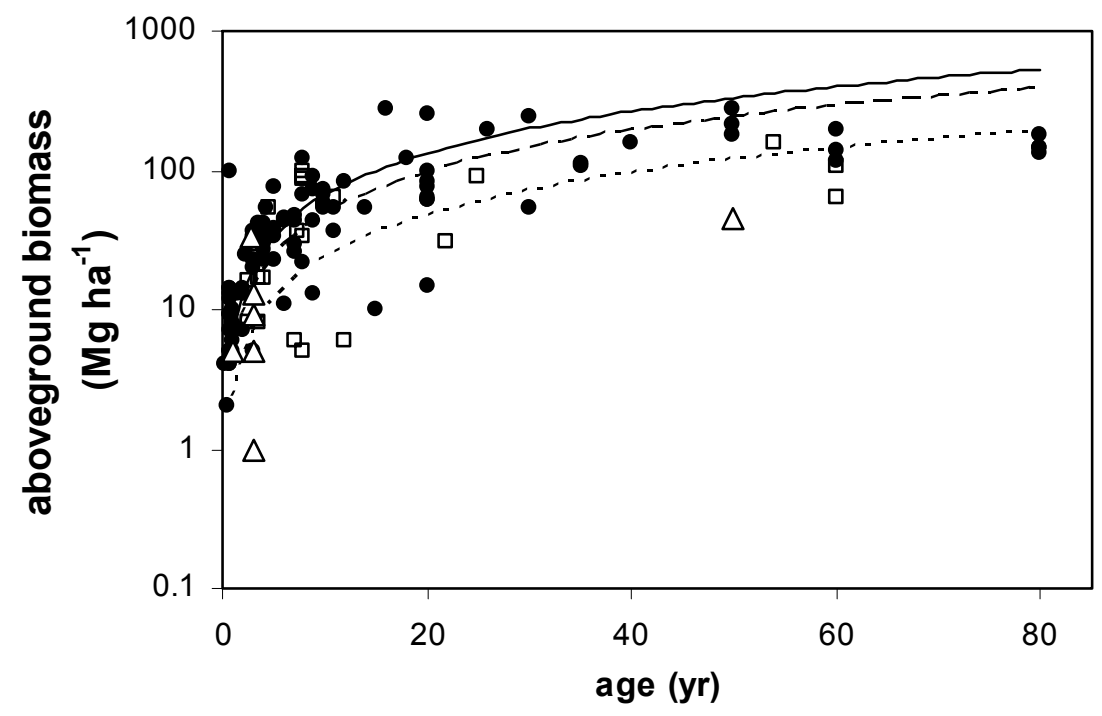

Figure 2 An integration of measures of biomass production by restored tropical forest ecosystems, growing on previously-cleared land (redrawn from data compiled by Silver et al., 2000; lines fitted using In-transformed biomass and age). Closed circles and continuous line: land previously used for agriculture; open squares and broken line: land previously used as pasture; triangles: land cleared but immediately abandoned

As a first approximation, the productivity of restored forests on mine lands may be expected to broadly equate to that shown in Figure 2 on land that had previously been cleared and abandoned. Cleared forest land, when compared with many mine soils, would offer the potential advantages of an intact soil profile with possibly only minor changes to its chemical properties and presumably with some retained biological activity. Changes that could be expected in these soils are depletion of nutrients and organic matter. By contrast, mine wastes are less likely to have optimal physical and chemical properties. However, they may be amended with fertilizers, organic matter or topsoil, to initially have equivalent or greater levels than abandoned lands, thus providing a fillip to assist the initial response.

An important aspect of Figure 2 is also the variability of productivity, e.g. a 20 -fold range of biomass after 10 years of growth. Whilst some of this variation is due to limitations imposed by soil type and climate, presumably most of the variation is caused by factors that can be influenced through management. Uncertainty about setting an evidence-based target range of productivity for a particular site warrants critical assessment of productivity-limiting factors, particularly where poor vegetation development has a negative impact on site sustainability.

Forest productivity is typically estimated from repeated sampling of tree diameter growth (Table 1). Growth rates of individual trees as well as the whole stands are of interest. Another measure of productivity, sampling of litterfall, is a classic scientific measure (Proctor, 1983) (Table 1). Sampling of litterfall is timeconsuming but offers the opportunity of chemical analysis to obtain useful information on nutrient cycling. Litterfall is a major pathway for return of nutrients from the vegetation to the soil and further information on decomposition can be obtained by observing fragmentation and incorporation of litter into the topsoil, by recording macro-invertebrate fauna and fungi with key roles in the process, or by direct measurement of disappearance of litter from litter bags (Chapman, 1986). Limitations to decomposition will lead to reduced 
nutrient uptake and tree growth. A new field procedure (P. Lavelle, pers. comm., 2005) examines the role of soil fauna, particularly worms, in creating soil aggregation. This is still a research technique, but could be adapted to use as a rapidly assessed indicator.

Changes in tree population structure and species composition provide insight into the rate and direction of development (Jasper et al., 2003). Forest tree species range from those of extremely shade-tolerant species, which survive under dense canopies, to extreme pioneers, which require large gaps for germination and growth. As rehabilitated forests develop, early successional (pioneer) trees should be gradually replaced by late successional (shade-tolerant) trees (Table 1).

The use of indicators of forest functioning is much less common than that of forest structure and composition. There is no established validated system to assess tropical forest functioning. Ecosystem Function Analysis (EFA) (Ludwig et al., 1997), incorporating LFA, was trialed as an indicator of forest health and vitality in two disturbed Australian forests but was abandoned in favour of assessments of crown condition of dominant tree species when foliar attack was shown to be the principle threatening process, due to an imbalance of insectivorous birds (Old et al., 1999). Other locations may require different site-specific indicators, not listed in Table 1. For example, plants can be excellent probes for soil contaminants/metals. At Grasberg, (West Papua), a reported measure is plant metal uptake, with reference to standards for human consumption.

For all monitoring approaches including LFA, it is essential that adjacent primary and secondary forests are also monitored to generate reference data for rehabilitated areas. This is standard practice at sites such as KPC in Kalimantan, and is an essential component of LFA.

\subsection{Fauna indicators}

Fauna fulfill a number of important roles in the functioning of rain forest ecosystems, including nutrient cycling, pollination and predation, and may even represent a food source for local communities. As well as this, they have conservation value in their own right. All of these roles need to be taken into account when determining which aspects of faunal succession in mined areas need to be monitored, and what are the most appropriate indicators. Logically, fauna monitoring must come late in the monitoring sequence, given their dependence on a vegetation community, which in turn depends strongly on appropriate soil conditions.

Very few studies have addressed the use of fauna as indicators for measuring post-mining ecosystem recovery in tropical rain forest communities (Jansen, 1997; Jasper et al., 2003). As exceptions, Majer (1992, 1996) conducted detailed studies of ant recolonisation following rehabilitation of bauxite mined areas at Trombetas and Poços de Caldas, in Brazilian rain forest. Within five years at Trombetas, the number of ant species in rehabilitation matched those recorded in some unmined sites. However, from the data it was inferred that the full range of habitat requirements had not been restored after 11 years of revegetation (Majer 1996). In addition, there was evidence to suggest that ant species richness built up most rapidly under mixed local plant species, rather than a Eucalyptus monoculture (Majer, 1992). The role of soil fauna in determining ecosystem function has been reviewed by Lavelle (1997). It is highly likely that earthworms would be excellent indicators as their role in tropical ecosystems has been well-researched.

Passell (2000) surveyed birds in 1-3 year old restored areas in Indonesian tin mines and in secondary forest reference sites. Although less detailed than the Majer (1996) study, Passell's work showed that simple indicators can be used to illustrate trends in avifaunal community development of rehabilitated mines, and such indicators acquire "umbrella" status. None of these studies addressed in detail what other aspects of ecosystem development are indicated by the parameters recorded. For greatest value, an "umbrella" measure should consistently demonstrate trends in other variables so that these do not need to be measured separately (Jasper et al., 2003).

One example of fauna monitoring is that recommended by EMRC (1999b) for KPC to assess faunal return into rehabilitation following coal mining in rain forest of east Kalimantan. It was recommended that that the key groups of birds, mammals, reptiles, frogs, ants and termites be monitored. Different groups reflect distinct aspects of ecosystem structure and function. EMRC (1999b) also recommended that the fauna and vegetation monitoring program be linked, and detailed records of rehabilitation operations be kept so that observed trends could be understood. 
One of the most important issues relating to the use of fauna as indicators is the fact that different faunal groups demonstrate very different successional trends in mine sites (Jasper et al., 2003) and that no single indicator can be used to illustrate trends in all faunal groups. As an extension of that, it has been demonstrated on particular mines that correlations exist between some measured parameters of the mammal fauna and some vegetation parameters. However, in most cases it is not known in advance what these correlations are, so it is not possible to use mammal survey data alone as a surrogate of any particular ecosystem parameter. Appropriate scale for monitoring large fauna remains an issue, and reliable data will often require considerable commitment of resources.

Several studies of bird re-colonisation of mined areas have demonstrated positive statistical associations between measured bird community parameters and particular plant parameters, especially plant productivity and floristic diversity. Therefore bird communities in mine rehabilitation may provide a good indication of the extent to which pre-mining forest ecosystems have been re-established. On the other hand, the continued absence of birds does not, of itself, identify a problem or the means of dealing with it.

\subsection{Landscape Function Analysis}

The LFA approach involves assessing how well the landscape is performing as a bio-physical system. In essence, LFA assesses the effectiveness of the retention and use of vital resources such as water, nutrients, topsoil and the seed pool. Landscapes are classified along a continuum from "functional" (efficient retention and use) to "dysfunctional" (resources are lost from the system). The procedure uses indicators which look at processes operating at the soil surface such as crust formation, infiltration, runoff, erosion, litter decomposition and slaking. The indicators are a mix of physical and biological processes. The suite of indicators was selected to provide information about ecosystem function as defined by Ludwig et al. (1997).

There are two sets of indicators in Landscape Function Analysis: Firstly, at a hillslope scale, there are six indicators reflecting the manner in which vital resources either flow out of the landscape or are retained and utilized. Secondly, at a finer scale there are 11 soil surface indicators that examine surface processes. Spreadsheets provided with the procedure provide processed information at both scales, as well as integration at the hillslope scale. Three major indices arise from the analysis: erosion stability, infiltration/runoff and nutrient cycling. These indices have been related to measured soil properties at a range of mines, including some in tropical moist forests.

The procedure aims to address the ecosystem as a bio-physical system, rather than an assemblage of biota. The LFA approach was originally developed in Australian rangelands, and therefore could be expected to be most applicable in that environment. Research with LFA has been conducted in moist tropical ecosystems (McGuire and Green, 2000; Tongway and Hindley, 2003; Setyawan, 2005) at early stages of rehabilitation. These studies showed that the biological changes were very rapid (Figure 3), needing frequent monitoring to capture the rapid progress of ecosystem development, which was characterized by complete ground cover within the first three weeks and erosion being strongly attenuated by this growth. Application to the wet-dry tropics over somewhat longer timescales was described in Tongway and Hindley (2003).

At the Kelian mine, Setyawan (2005) compared LFA values with specific measures of soil properties, including total soil $\mathrm{C}$ and $\mathrm{N}$, extractable $\mathrm{P}$, mineralisable $\mathrm{N}$, and microbial respiration, together with physical properties of bulk density, particle size distribution, and water-stable aggregates. A sequence of ages of rehabilitation was included in the study. The results clearly indicate that there can be a very rapid recovery of both measured soil properties and of LFA indices in tropical moist forests. For example total and mineralisable $\mathrm{N}$ increased with age of rehabilitation, to the point that it exceeded values of an analogue site (Figure 4). Total $\mathrm{N}$ in the rehabilitated soils was strongly correlated with total $\mathrm{C}$ in both rehabilitated and analogue forest soil, but with lower C:N ratios in rehabilitated soils than in the forest soil (Setyawan, 2005). The rapid accumulation of organic matter in these soils was also associated with improved values for structural properties such as aggregate stability. Such rapid responses in soil properties reflects the high plant productivity in these tropical environments, and is a major point of difference with recovery rates in temperate or arid rehabilitation. For example, changes in total soil $\mathrm{C}$ in jarrah forest soils were too slow to be of value as an indicator of soil recovery, but more sensitive measures such as microbial biomass do have a quicker response time (Jasper, 2002). 


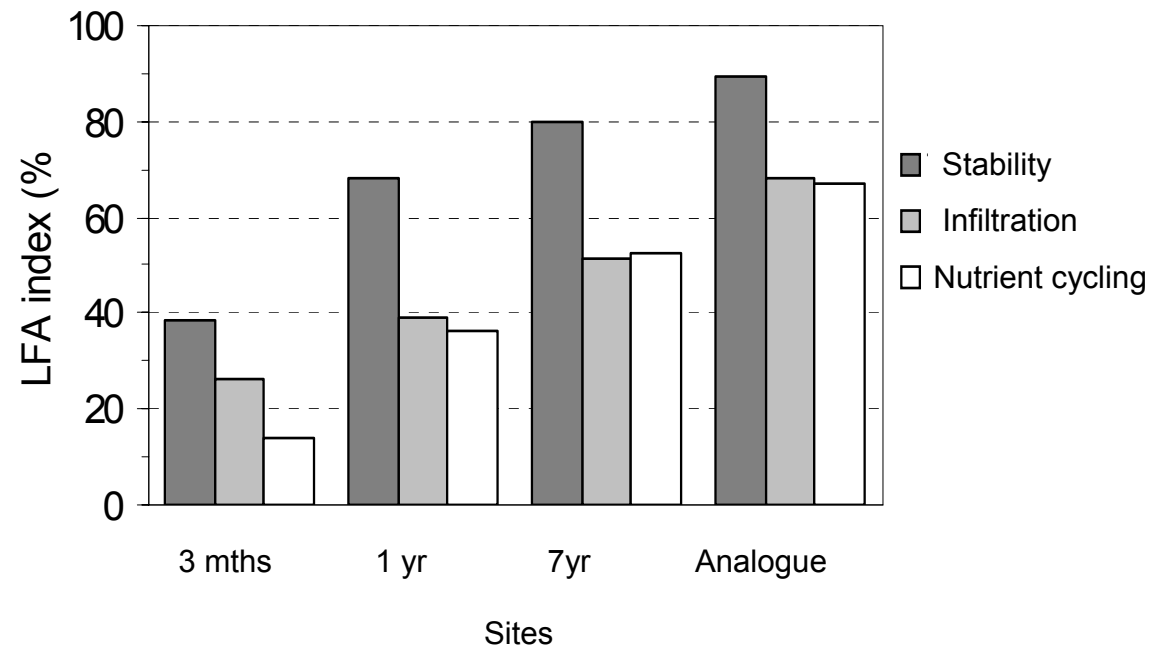

Figure 3 A comparison of values of the stability, infiltration and nutrient cycling indices for three rehabilitated areas and an analogue site at Kelian Equatorial Mining in Kalimantan (from Setyawan, 2005)
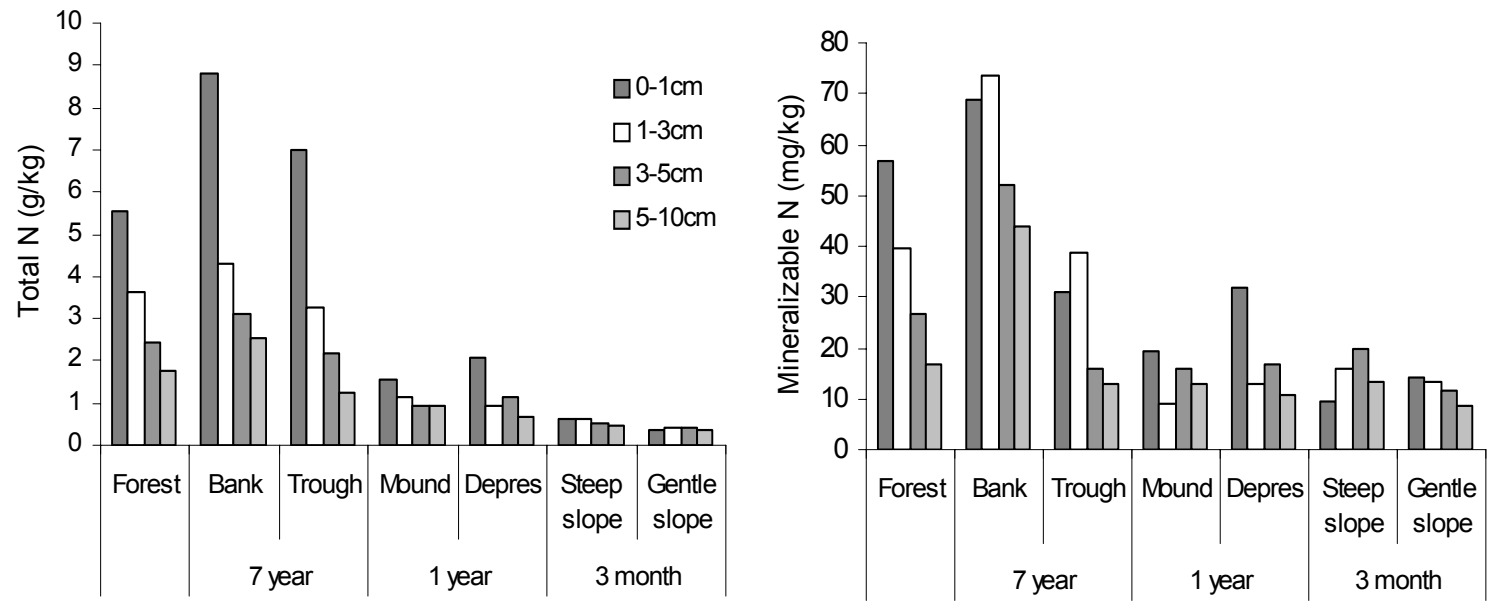

Figure 4 Total $\mathbf{N}$ and mineralisable $\mathrm{N}$ in three rehabilitated sites and a reference forest site at Kelian Equatorial Mining in Kalimantan (from Setyawan, 2005). Data for each rehabilitated site were segregated into local topographic zones, reflecting either ripping of the site or paddock dumping

The vigorous growth response of vegetation in the tropical environment at Kelian means that plant measures such as foliar cover and plant litter also increase rapidly. These measures are important contributors to LFA indices, given that they contribute strongly to soil protection, soil organic matter inputs and nutrient cycling. Therefore, as could be expected, experience at Kelian is that the LFA indices also increase very quickly in young rehabilitation (Setyawan, 2005). As an example, the calculated Nutrient Cycling Index increased very quickly within the first year, but then increased only slowly towards the level recorded for a forest reference site (Figure 5). In the same soils, soil $\mathrm{C}$, which closely relates to nutrient pools such as mineralisable $\mathrm{N}$ in these soils, increased more slowly, resulting in a non-linear relationship with the Nutrient Cycling Index. Similar responses were recorded for LFA data on Misima (D. Tongway, unpublished). In similar studies in temperate, wet/dry forests or arid areas, these relationships are more typically linear (Tongway and Hindley, 2003). It appears likely that some adjustments to frequency of monitoring, or to re-weighting the inputs into the calculated indices may be appropriate for tropical ecosystems. 

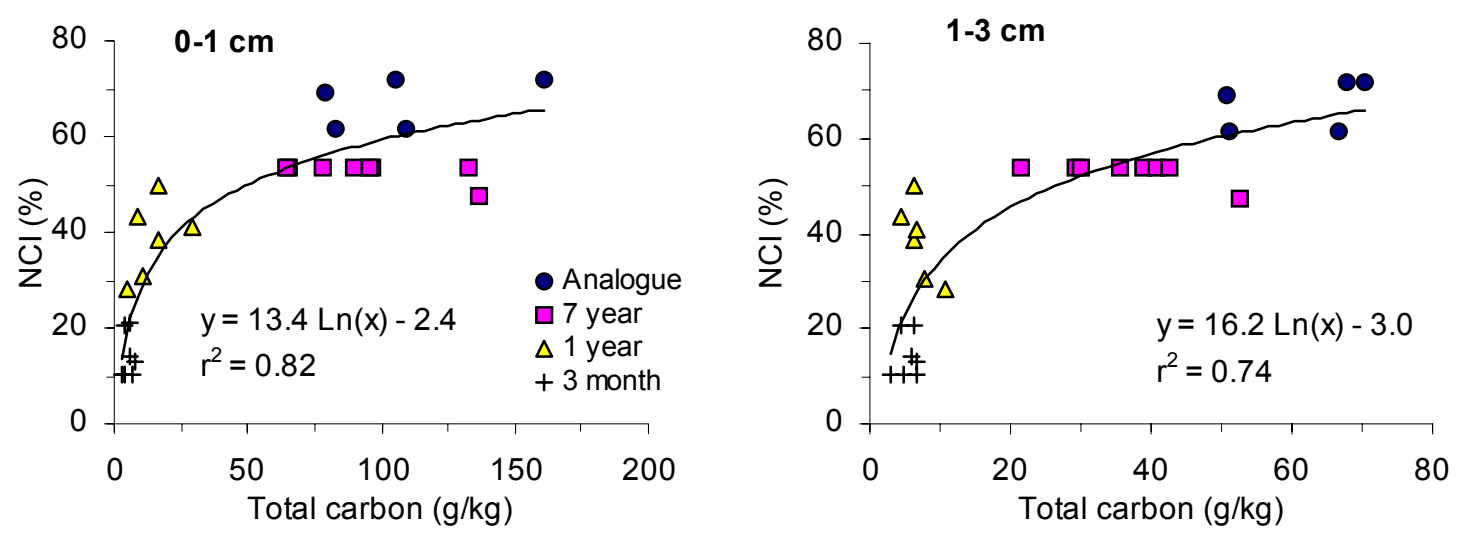

Figure $5 \quad$ Values for the nutrient cycling index derived from Landscape Function Analysis of three rehabilitated sites at Kelian Equatorial Mining, in comparison to total soil $C$ at 0 to $1 \mathrm{~cm}$, or 1 to $3 \mathrm{~cm}$ depth, at the same sites (from Setyawan, 2005)

\section{CONCLUSIONS}

The case studies examined for this paper highlight the diversity of environments, biota, mining impacts and rehabilitation objectives in tropical moist forest regions. Nevertheless, these environments have distinct properties compared with temperate and (semi-)arid environments. In particular, ecosystem development in the wet tropics can be very fast. At the same time, failure of rehabilitation efforts can also be very fast. As in other ecosystems, identification of short-term as well as long-term rehabilitation objectives is essential. In the tropical environment, more intensive monitoring may be necessary in the first few months.

This paper provides guidelines regarding desirable properties of rehabilitation performance indicators, and identifies a set of key soil, vegetation and fauna indicators that can provide vital insights into rehabilitated ecosystem structure and function. Integrated approaches such as Landscape Function Analysis also have potential in moist tropical forests, but the definition of synthetic functional indices may need to be reassessed in order to ensure that they have the ability to capture the rate and nature of the key processes tropical moist environments.

\section{ACKNOWLEDGEMENTS}

This review was derived from reports prepared for Misima Mines Limited (Barrick Gold) and for Ok Tedi Mining Limited. The support from these companies and environmental staff at each site is gratefully acknowledged.

\section{REFERENCES}

Burghouts, T., Ernsting, G., Korthals, G. and De Vries, T. (1992) Litterfall, leaf litter decomposition and litter invertebrates in primary and selectively logged dipterocarp forest in Sabah, Malaysia. Philosophical Transactions: Biological Sciences 335(1275), pp. 407-16.

Burnham, C.P. (1984) The forest environment: Soils. In: Tropical rain forests of the Far East. T.C. Whitmore (ed). Clarendon Press, Oxford.

Burnham, C.P. (1989) Pedological processes and nutrient supply from parent material in tropical soils. In: Mineral nutrients in tropical forest and savanna ecosystems. J. Proctor (ed). Special Publication Series of the British Ecological Society Number 9. Blackwell Scientific Publications, Oxford.

Chambers, J.C., Brown, R.W. and Williams, B.D. (1994) An evaluation of reclamation success on Idaho's phosphate mines. Restoration Ecology 2, pp. 4-16.

Chapman, S.B. (1986) Production ecology and nutrient budgets. In: Methods in Plant Ecology. 2nd edition. P.D. Moore and S.B. Chapman (eds), pp. 1-59. Blackwell Scientific Publications, Oxford. 
Ehrenfeld, J.G. (2000) Defining the limits of restoration: The Needs for Realistic Goals. Restoration Ecology 8, pp. $2-9$.

EMRC (1999a) Results of the initial and long term monitoring of areas rehabilitated following coal mining operations at Sangatta, East Kalimantan. Environmental Management and Research Consultants. May 1999.

EMRC (1999b) PT Kaltim Prima Coal: A recommended monitoring program for areas rehabilitated following coal mining operations at Sangatta, East Kalimantan. Consulting report prepared for PT Kaltim Prima Coal, Sangatta, East Kalimantan, Indonesia. June 1999.

Grubb, P.J. (1989) Mineral nutrition and soil fertility in tropical rain forests. In: Tropical Forests: Management and Ecology. A.E. Lugo and C. Lowe (eds). Ecological Studies 112, Springer-Verlag, New York.

Hartshorn, G.S. and Whitmore, J.L. (1999) Ecosystems of the disturbed ground. In: Ecosystems of the World 16. L.R. Walker (ed). Elsevier, New York.

Holl, K.D. and Cairns, J.Jr. (2002) Monitoring and appraisal. In: Handbook of Ecological Restoration, Volume 1, Principles of Restoration. M.R. Perrow and A.J. Davy (eds). Cambridge University Press.

Jansen, A. (1997) Terrestrial invertebrate community structure as an indicator of the success of a tropical rainforest restoration project. Restoration Ecology 5, pp. 115-24.

Jasper, D. (2002) Soil indicators and monitoring of rehabilitation. In: Encyclopaedia of Soil Science. R. Lal (ed). Marcel Dekker, New York.

Jasper, D.A., Nichols, O.G. and Veneklaas, E. (2003) A review of indicators of success for rehabilitated tropical forest systems. Report to Misima Mines Limited prepared by Outback Ecology Services, February 2003. Perth, Western Australia.

Karlen, D.L., Wollenhaupt, N.C., Erbach, D.C., Berry, E.C., Swan, J.B., Eash, N.S. and Jordahl, J.L. (1994) Crop residue effects on soil quality following 10-years of no-till corn. Soil and Tillage Research 31, pp. 149-167.

Lavelle, P. (1997) Faunal Activities and Soil Processes: Adaptive Strategies that determine Ecosystem Function. Advances in Ecological Research 27, pp. 93-132.

Losos, E.C. and Leigh, E.G. (2004) Tropical forest diversity and dynamism: findings from a large-scale plot network. The University of Chicago Press, Chicago.

Ludwig, J., Tongway, D., Freudenberger, D., Noble, J. and Hodgkinson, K. (eds) (1997) Landscape ecology function and management: principles from Australia's rangelands (now available only on CD from Norman Hindley, CSIRO Sustainable Ecosystems, GPO 284 Canberra City 2601 ACT, Australia, norman.hindley@csiro.au).

Majer, J.D. (1992) Ant recolonisation of rehabilitated bauxite mines of Poços de Caldas, Brazil. Journal of Tropical Ecology 81, pp. 97-108.

Majer, J.D. (1996) Ant recolonisation of rehabilitated bauxite mines at Trombetas, Para, Brazil. Journal of Tropical Ecology 12, pp. 257-273.

McGuire, G. and Green, A. (2000) Mitigating mine closure risks in a developing community. In: Proceedings of Minerals Council of Australia Environmental Workshop, Perth. October 2000. Mineral Council of Australia, Dickson, Australia.

Old, K., Coops, N., Tongway, D., Stone, C. and Smith, I. (1999) Scoping Study for Montreal Process National Indicator of Forest Health and Vitality 3.1.c. Department of Agriculture Fisheries and Forestry, Australia.

Parrotta, J.A. (2002) Restoration and management of degraded tropical forest landscapes. In: Modern Trends in Applied Terrestrial Ecology. R.S. Ambasht and N.K. Ambasht (eds), pp. 135-148. Kluwer Academic/Plenum Press, New York.

Parrotta, J.A. and Knowles O.H. (2001) Restoring tropical forests on lands mined for bauxite: examples from the Brazilian Amazon. Ecological Engineering. 17, pp. 219-239.

Passell, H.D. (2000) Recovery of bird species in minimally restored Indonesian tin strip mines. Restoration Ecology 8 , pp. 112-118.

Proctor, J. (1983) Tropical forest litterfall. I. Problems of data comparison. In: Tropical Rain Forest: Ecology and Management. S.L. Sutton, T.C. Whitmore and A.C. Chadwick (eds), pp. 267-273. Blackwell, Oxford.

Setyawan, D. (2005) Soil development, plant colonization and landscape function analysis for disturbed lands under natural and assisted rehabilitation. PhD Thesis. The University of Western Australia. 
Silver, W.L., Ostertag, R. and Lugo, A.E. (2000) The potential for carbon sequestration through reforestation of abandoned tropical agricultural and pasture lands. Restoration Ecology 8, pp. 394-407.

Tongway, D.J. and Hindley, N.L. (1995) Assessment of soil condition of tropical grasslands. CSIRO Division of Wildlife and Ecology, Canberra.

Tongway, D., Hindley, N., Ludwig, J., Kearns, A. and Barnett, G. (1997) Early indicators of ecosystem rehabilitation on selected minesites. In: Proceedings of 22nd Annual Minerals Council of Australia Environmental Workshop, Adelaide. October 1997, pp. 494-505. Mineral Council of Australia, Dickson, Australia.

Tongway, D.J. and Murphy, D. (1999) Principles for designed landscapes and monitoring of ecosystem development in rangelands affected by mining. In VIth International Rangeland Congress Proceedings with International Rangeland Congress Inc. Aitkenvale Queensland, Australia.

Tongway, D.J. and Hindley, N.L. (2003) Indicators of Ecosystem Rehabilitation Success. Stage Two- Verification of EFA Indicators. Final Report for the Australian Centre for Mining Environmental Research. CSIRO Sustainable Ecosystems, Canberra.

Tongway, D.J. and Hindley, N.L. (2004) Landscape Function Analysis: procedures for monitoring and assessing landscapes, with special reference to minesites and rangelands. CSIRO Sustainable Ecosystems, Canberra, Australia.

Vincelette, M. (2003) Restoration of Tropical Ecosystems in Madagascar after Mining: Littoral Forests and WetlandsApproaches and Techniques. In: Abstracts- Preservation and ecological restoration in tropical mining environments, 15th July 2003, New Caledonia, pp. 136-137. IRD Centre, Noumea, New Caledonia.

Ward, S.C. (2000) Soil development on rehabilitated bauxite mines in south-west Australia. Australian Journal of Soil Research 38, pp. 453-64.

Ward, S.C. and Koch, J.M. (1996) Biomass and nutrient distribution in a 15.5 year old forest growing on a rehabilitated bauxite mine. Australian Journal of Ecology. 21, pp. 309-315.

Whitmore, T.C. (1984) The forest environment: soils. In: Tropical rain forests of the Far East. T.C. Whitmore (ed). Clarendon Press, Oxford. 